\title{
LUPUS Thoughts on COVID-19 and autoimmune diseases
}

\author{
Anca D Askanase (1),${ }^{1}$ Leila Khalili, ${ }^{1}$ Jill P Buyon ${ }^{2}$
}

To cite: Askanase AD, Khalili L, Buyon JP. Thoughts on COVID-19 and autoimmune diseases. Lupus Science \& Medicine 2020;7:e000396. doi:10.1136/ lupus-2020-000396

Received 17 March 2020 Accepted 20 March 2020

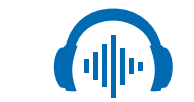

Listen to Podcast lupus.bmj.com

Check for updates

(C) Author(s) (or their employer(s)) 2020. Re-use permitted under CC BY-NC. No commercial re-use. See rights and permissions. Published by BMJ.

${ }^{1}$ Department of Rheumatology, Columbia University Medical Center, New York, New York, USA ${ }^{2}$ Department of Rheumatology, NYU Langone Health, New York, New York, USA

Correspondence to

Dr Anca D Askanase; ada20@ cumc.columbia.edu

\section{ABSTRACT}

Over the 2 months since coronavirus first appeared in China, cases have emerged on every continent, and it is clear that patients with autoimmune diseases might also be affected. Coronavirus disease 2019 (COVID-19) is a highly contagious viral illness with a mortality rate approaching $2 \%$. Here we discuss the challenges that patients with autoimmune diseases might face and the information on using immunomodulatory therapies like chloroquine, tocilizumab and baricitinib to quench the cytokine storm in patients with very severe COVID-19 pneumonia.

In a time of uncertainty, where fake news easily becomes 'reality', the novel coronavirus disease 2019 (COVID-19) pandemic poses a great challenge to physicians and their at-risk patients. While information steadily streams in through all possible news and social media channels, physicians and the scientific community are in a unique position to advise, caution and comfort their patients. The lupus landscape has always required navigating unique challenges, and the COVID-19 pandemic is no different. So, what should patients with lupus, many of whom are immunosuppressed by the illness per se and the medications used to treat it, do to prepare for and combat this novel coronavirus, and what should their doctors tell them about the virus, and accompanying news scares, that are rapidly disseminating through the internet?

Over the 2 months since coronavirus first emerged in China, the US medical system has remained more watchful than actionable, but now that cases have emerged on every continent, it is clear that it is only a matter of time before every country and major urban centre will be affected. Data suggest a highly contagious viral illness with a mortality rate approaching 2\%, echoing the Spanish flu of 1918. As of 8 March 2020, the WHO reported over 100000 confirmed cases of COVID-19 globally. ${ }^{1}$ The US Centers for Disease Control and Prevention (CDC) reported 423 cases of COVID-19 in the USA across 35 states, with 19 deaths. ${ }^{2}$ Is the US medical system ready?
Coronaviruses are a family of viruses, including the common cold, which typically cause mild to moderate upper respiratory tract symptoms. These viruses are zoonotic, often originally circulating among animals; they occasionally spill over to humans through contact. There are currently seven coronaviruses known to cause human disease, three of which (severe acute respiratory syndrome, Middle East respiratory syndrome and COVID-19) are known to cause moderate to severe disease in humans. ${ }^{3}$ Similar to other coronaviruses, COVID-19 has an incubation period of 2-14 days and causes fever, fatigue, cough and shortness of breath, but it may also progress to more severe respiratory illness. ${ }^{4}$ Additionally, many of those infected with the virus may never show any symptoms at all. These individuals are contagious despite being clinically asymptomatic, which contributes to the spread of disease. COVID-19 was initially thought to be solely transmitted through respiratory shedding; however, COVID-19 has also been found in anal swabs suggesting an additional oral-faecal route of transmission. ${ }^{5}$

Until recently, the positive cases of COVID-19 in the USA have either travelled recently to areas with high COVID-19 activity or had contact with those who have tested positive for COVID-19. However, in the past week, the USA has started to report cases of community-spread COVID-19 (ie, cases that cannot be traced to travel or a known contact). The quickly spreading virus, the emergence of community-acquired cases and the possibility of asymptomatic carrier transmission ${ }^{6}$ are of concern to our patients with SLE who may be susceptible to the more severe manifestations of coronavirus, such as pneumonia. Of course, whether individuals with SLE are more susceptible is not known. It is even possible that the elevated type I interferon (IFN), that is characteristic of many patients, has a protective effect. ${ }^{7}$ Interestingly, very early literature supported that factors in SLE sera confer acid lability to IFN alpha; 
however, the consequences of this biochemical property to antiviral activity remain unexplored. ${ }^{89}$

While there have not been many studies looking at respiratory complications of human coronaviruses in immunocompromised patients, patients with autoimmune diseases or patients taking immunosuppressant medication, there have been case reports of other types of coronaviruses causing pneumonia in immunocompromised patients. ${ }^{10}$ However, COVID-19 has thus far caused viral pneumonia and acute respiratory distress syndrome (ARDS) in individuals who are not immunocompromised ${ }^{11}$ and so the risk of such complications is certainly at the forefront when counselling immunocompromised patients.

Helpful data are slowly materialising, including case reports quickly put together by doctors at the epicentre of the epidemic in China. Data on the radiographic findings were reported in the journal Radiology and indicate that COVID-19 pneumonia presents as bilateral ground glass opacities followed by increased consolidations without cavitation or effusion that can lead to ARDS and death. ${ }^{12}$ The pathological findings from one autopsy were published in the Lancet. ${ }^{13}$ The main feature is that of diffuse alveolar damage, interstitial mononuclear/ lymphocytic infiltrates and hyaline membrane formation. Perhaps of concern for patients with SLE, lymphopaenia (which is common in lupus as one of the criteria for the disease itself and/or medications used to treat) is associated with disease severity and mortality. ${ }^{8}$

Per the CDC, treatment options for COVID-19 are currently infection control measures and supportive management of complications. The CDC recommends generally avoiding corticosteroids due to its possible prolonging of viral replication. Remdesivir (an investigational antiviral drug) and chloroquine (an antimalarial drug frequently used in the treatment of SLE), demonstrated in vitro activity against COVID-19. ${ }^{14}$ A clinical trial is underway in China for the use of remdesivir in COVID-19. Additionally, the Food and Drug Administration approved a National Institutes of Health adaptive randomised controlled clinical trial of investigational therapeutics (the first investigational drug being remdesivir) for patients hospitalised with COVID-19. ${ }^{4}$

Recently, the American College of Rheumatology suggested that patients should 'talk to their rheumatologist or rheumatology professional prior to discontinuing any medications... providers should follow their current practice for interrupting therapy during episodes of infection'. ${ }^{15}$ However, there are currently no official guidelines on holding immunosuppression in patients with autoimmune diseases at risk for contracting COVID-19. For outpatients with known contact, who are under quarantine and for certain patients who are experiencing symptoms of COVID-19 and are under investigation for the disease, it may be prudent to hold maintenance immunosuppression for 2 weeks following contact or travel. Patients with autoimmune diseases without clear evidence of exposure should continue their treatments. As always, this should be based on a conversation (including a basic evaluation of COVID-19 risk factors and a risk/benefit analysis) between the patient and the rheumatologist and should be a joint decision. Basic measures to minimise exposure should be reviewed with our patients and include cancelling non-essential travel, avoiding gatherings, reducing contact with others, skipping hugs and handshakes and frequent hand hygiene. Patients complaining of fever and cough should be advised not to come for their appointments and might have to be turned away since they risk infecting others. However, patients with fever, cough and shortness of breath should be directed to the emergency room, where they can be tested, evaluated and treated. Many hospitals are encouraging or mandating telemedicine visits; this may soon extend to everyone.

We generally consider hydroxychloroquine (HCQ) and chloroquine as being effective in lupus, in part due to inhibition of type I interferon (considered our innate first-line defence antiviral response), which has often raised concern about susceptibility to viral infection. However, data are accumulating at a very rapid rate that there may be a paradox. By raising endosomal $\mathrm{pH}$ (one of the mechanisms that leads to decreased toll like receptor (TLR) ligation and decreased IFN) COVID-19 viral replication itself is decreased. ${ }^{16}$ Since acidification is crucial for endosome maturation and function, Liu and colleagues ${ }^{17}$ suggest that endosome maturation could be blocked at intermediate stages of endocytosis, which would then result in decreased transport of virions to the ultimate releasing site. A study by Gao $e t \mathrm{al}^{18}$ suggests that chloroquine has efficacy against the associated pneumonia in multicentre clinical trials conducted in China. Additionally, there have been two other small trials that raise more questions than provide definitive answers to the question of hydroxychloroquine efficacy in COVID-19. ${ }^{19}{ }^{20}$ Specifically, the study by Gautret et al was a single-arm protocol in which 20 confirmed COVID-19 patients were given $600 \mathrm{mg}$ of HCQ daily (and is some cases azithromycin), and their viral load in nasopharyngeal swabs was tested. Six patients were asymptomatic, 22 had upper respiratory tract infection symptoms and 8 had lower respiratory tract infection symptoms. A significant reduction of viral carriage was reported. Of note, levels of HCQ were in accord or lower than those seen in our lupus patients prescribed $5 \mathrm{mg} / \mathrm{kg}$. The heterogeneity of the patients included, selection of the control population, high rate of lost to follow-up and handling of missing observations raise concerns about their conclusions. ${ }^{19}$ The other trial, a 30-patient, placebo-controlled study of HCQ in patients with relatively mild COVID-19 infections, using $400 \mathrm{mg}$ of HCQ daily, did not show any differences between drug and placebo groups in viral clearance, duration of hospitalisation or radiological progression of COVID-19 pneumonia. ${ }^{20}$

Regardless, this is an excellent time to reinforce compliance with hydroxychloroquine in SLE.

In a paper from 2017, Channappanavar et $a l^{21}$ describe a pathogenic cascade that leads to ARDS and death; this 
mechanism is likely operative in COVID-19 infections. These authors propose a scenario in which viral replication leads to a delayed interferon response, accumulation and activation of monocyte/macrophages and neutrophils, which in aggregate result in an exaggerated immune response responsible for the alveolar and endothelial apoptosis. There is certainly a complexity in the contribution of type I IFNs with regard to early and late responses. The former may restrict virus replication through induction of interferon-stimulated genes, while the latter can exacerbate disease by enhancing recruitment and function of macrophages and other innate immune cell. ${ }^{21}$ Dysregulation of inflammatory responses initiates pulmonary damage that leads to ARDS. Data from China suggest that using immunomodulatory therapies like chloroquine, ${ }^{17}$ tocilizumab ${ }^{22}$ (preferred right now because of the track record) and baricitinib ${ }^{23}$ can quench the cytokine storm that ensues in patients with very severe COVID-19 pneumonia. ${ }^{24}$

Patients admitted for severe COVID-19 infections should probably hold maintenance therapies; these decisions are best left to the rheumatology/infectious disease teams taking care of them. Rheumatologists and infectious disease specialists should be working together in this epidemic as clear data are not available, thus making recommendations speculative.

There is much to learn about the interplay between infections, autoimmune diseases and immune therapies. Leveraging knowledge of the innate and adaptive immune system will be critical as we navigate through these challenging times.

Contributors Authors have contributed equally to this manuscript.

Funding The authors have not declared a specific grant for this research from any funding agency in the public, commercial or not-for-profit sectors.

Competing interests None declared.

Patient and public involvement Patients and/or the public were not involved in the design, or conduct, or reporting, or dissemination plans of this research. Patient consent for publication Not required.

Provenance and peer review Not commissioned; internally peer reviewed.

Open access This is an open access article distributed in accordance with the Creative Commons Attribution Non Commercial (CC BY-NC 4.0) license, which permits others to distribute, remix, adapt, build upon this work non-commercially, and license their derivative works on different terms, provided the original work is properly cited, appropriate credit is given, any changes made indicated, and the use is non-commercial. See: http://creativecommons.org/licenses/by-nc/4.0/.

ORCID iD

Anca D Askanase http://orcid.org/0000-0003-4597-5023

\section{REFERENCES}

1 World Health Organization. Coronavirus disease 2019 (COVID-19) situation report 48, 2020. Available: https://www.who.int/docs/ default-source/coronaviruse/situation-reports/20200308-sitrep-48covid-19.pdf?sfvrsn=16f7ccef_4

2 Centers for Disease Control and Prevention. Coronavirus disease 2019 (COVID-19) in the U.S, 2020. Available: https://www.cdc.gov/ coronavirus/2019-ncov/cases-in-us.html\#investigation

3 National Institute of Allergy and Infectious Diseases. Coronaviruses, 2020. Available: https://www.niaid.nih.gov/diseases-conditions/ coronaviruses

4 Centers for Disease Control and Prevention. Interim clinical guidance for management of patients with confirmed coronavirus disease (COVID-19), 2020. Available: https://www.cdc.gov/ coronavirus/2019-ncov/hcp/clinical-guidance-managementpatients.html

5 Zhang W, Du R-H, Li B, et al. Molecular and serological investigation of 2019-nCoV infected patients: implication of multiple shedding routes. Emerg Microbes Infect 2020;9:386-9.

6 Bai Y, Yao L, Wei T, et al. Presumed asymptomatic carrier transmission of COVID-19. JAMA 2020.

7 Niewold TB. Interferon alpha as a primary pathogenic factor in human lupus. J Interferon Cytokine Res 2011;31:887-92.

8 Yee AM, Buyon JP, Yip YK. Interferon alpha associated with systemic lupus erythematosus is not intrinsically acid labile. $J$ Exp Med 1989;169:987-93.

9 Preble O, Black R, Friedman R, et al. Systemic lupus erythematosus: presence in human serum of an unusual acid-labile leukocyte interferon. Science 1982;216:429-31.

10 Pene F, Merlat A, Vabret A, et al. Coronavirus 229E-related pneumonia in immunocompromised patients. Clin Infect Dis 2003;37:929-32.

11 Chen N, Zhou M, Dong X, et al. Epidemiological and clinical characteristics of 99 cases of 2019 novel coronavirus pneumonia in Wuhan, China: a descriptive study. Lancet 2020;395:507-13.

12 Pan F, Ye T, Sun P, et al. Time course of lung changes on chest CT during recovery from 2019 novel coronavirus (COVID-19) pneumonia. Radiology 2020:200370.

13 Xu Z, Shi L, Wang Y, et al. Pathological findings of COVID-19 associated with acute respiratory distress syndrome. Lancet Respir Med 2020. doi:10.1016/S2213-2600(20)30076-X

14 Wang M, Cao R, Zhang L, et al. Remdesivir and chloroquine effectively inhibit the recently emerged novel coronavirus (2019nCoV) in vitro. Cell Res 2020;30:269-71.

15 American College of Rheumatology. A message from the ACR about coronavirus disease 2019 (COVID-19), 2020. Available: https://www. rheumatology.org/announcements

16 Yao X, Ye F, Zhang M, et al. In vitro antiviral activity and projection of optimized dosing design of hydroxychloroquine for the treatment of severe acute respiratory syndrome coronavirus 2 (SARS-CoV-2). Clin Infect Dis 2020.

17 Liu J, Cao R, Xu M, et al. Hydroxychloroquine, a less toxic derivative of chloroquine, is effective in inhibiting SARS-CoV-2 infection in vitro. Cell Discov 2020;6:16.

18 Gao J, Tian Z, Yang X. Breakthrough: chloroquine phosphate has shown apparent efficacy in treatment of COVID-19 associated pneumonia in clinical studies. Biosci Trends 2020;14:72-3.

19 Gautret P, Lagier J, Parola P, et al. Hydroxychloroquine and azithromycin as a treatment of COVI-19: results of an open-label non-randomized clinical trial. ScienceDirect 2020.

20 Chen J, Liu D, Liu L, et al. A pilot study of hydroxychloroquine in treatment of patients with common coronavirus disease-19 (COVID-19). Available: www.zjujournals.com/med/article/2020/10089292/20200108.shtml

21 Channappanavar R, Perlman S. Pathogenic human coronavirus infections: causes and consequences of cytokine storm and immunopathology. Semin Immunopathol 2017;39:529-39.

22 . Available: https://www.reuters.com/article/us-health-coronaviruschina-roche-hldg-idUSKBN2OROLF

23 Richardson P, Griffin I, Tucker C, et al. Baricitinib as potential treatment for 2019-nCoV acute respiratory disease. The Lancet 2020;395:e30-1.

24 Stebbing J, Phelan A, Griffin I, et al. COVID-19: combining antiviral and anti-inflammatory treatments. Lancet Infect Dis 2020;20:400-2. 